\title{
PENGELOLAAN WAKAF TUNAI
}

\author{
Muhyar Fanani \\ IAIN Walisongo Semarang \\ email: muhyar_fanani@yahoo.com
}

\begin{abstract}
Basic issue on waqaf is the management, especially on the management of cash money. The institutions having in charge for managing the waqaf of cash money, have some management specific characteristics and patterns. This study focused on the management of waqaf on cash money in three institution, TWI, PKPU, and BMM. Applying qualitative method, it is found that waqaf of cash money still has some problems to solve: the lack of dissemination about waqaf of cash money among society members, the lack of professional nāzir, no effective fundraising system, the weak managerial system, the low commitment on risk management, the unprotected purchasing power of money, and the variability on the distribution priority.

$* * *$

Permasalahan dasar waqf adalah menajemen, khususnya manajemen uang tunai. Lembaga yang berperan untuk mengelola waqf uang tunai memiliki beberapa karakteristik dan pola manajemen yang spesifik. Kajian ini memfokuskan pada manajemen waqf uang tunai di tiga lembaga: TWI, PKPU, dan BMM. Dengan menggunakan pendekatan kualitatif ditemukan bahwa waqf uang tunai masih meninggalkan beberapa persoalan yaitu: kurangnya diseminasi tentang waqf uang tunai di kalangan masyarakat, kurangnya jumlah nadzir yang profesional; tidak adanya sistem pencarian dana yang efektif, lemahnya sistem manajemen, kekuatan pembelian uang yang tidak terlindungi, dan variabilitas prioritas distribusi.
\end{abstract}

Keywords: manajemen, pengumpulan dana, modal, manajemen risiko, distribusi 


\section{A. Pendahuluan}

Wakaf uang di Indonesia mengalami berbagai kendala baik dalam tataran sosialisasi, aplikasi, maupun manajemennya. Kendala yang paling mencolok bagi pemberdayaan wakaf uang adalah persoalan manajemen. Masyarakat Muslim Indonesia belum memiliki tradisi yang kuat untuk memaksimalkan pengelolaan wakaf uang agar dapat membantu peningkatan kesejahteraan umat. Untuk mengetahui lebih jauh tentang problem dan solusi pengelolaan wakaf uang di Indonesia, tulisan ini mengkaji tiga lembaga nāẓir perintis wakaf uang di Indonesia. Tiga lembaga itu adalah: Lembaga Tabung Wakaf Indonesia (TWI), Pos Keadilan Peduli Umat (PKPU), dan Baitul Mal Muamalat (BMM). Ketiga lembaga itu berpusat di Jakarta dan memiliki cabang di berbagai daerah, kecuali TWI yang tak membuka cabang. Persoalan seputar strategi penggalangan dana dan mekanisme pertanggungjawabannya, strategi menjaga pokok harta, strategi menghindari risiko kerugian, strategi pembelanjaan keuntungan, problem dan solusi manajerial, serta proyeksi 25 tahun ke depan diurai agar bisa diketahui masyarakat luas.

\section{B. Manajemen Pengelolaan Wakaf Uang di TWI, PKPU, dan BMM}

Di Indonesia, sesuai dengan perundangan yang ada, penerima wakaf uang adalah LKS-PWU. Namun fenomena wakaf uang sesungguhnya sudah ada sejak sebelum penunjukan LKS-PWU oleh Menag pada tahun 2008. TWI, PKPU, dan BMM merupakan lembaga nāzir wakaf terdepan yang telah melaksanakan wakaf uang sejak tahun 2002-an.

\section{Tabung Wakaf Indonesia (TWI)}

TWI merupakan lembaga nāẓir wakaf yang didirikan oleh Dompet Dhu'afa' Republika yang berdiri pada tanggal 14 Juli 2005. Aktivitas TWI berkisar pada sosialisasi, edukasi dan advokasi wakaf kepada masyarakat sekaligus sebagai lembaga penampung dan pengelola harta wakaf. Untuk membiayai operasional wakaf, TWI menyisihkan 5-10 \% hasil untuk operasional nāzir.

Visi dan Misi TWI adalah menjadi lembaga nāẓir wakaf berorientasi global yang mampu menjadikan wakaf sebagai salah satu pilar kebangkitan 
ekonomi umat yang berbasiskan pada sistem ekonomi berkeadilan. ${ }^{1}$ TWI juga memiliki tekad untuk mendorong pertumbuhan ekonomi umat serta optimalisasi peran wakaf dalam sektor sosial dan ekonomi produktif.

TWI merupakan nāzir wakaf produktif terdepan di Indonesia. Ia menerima wakaf uang dari masyarakat. Wakaf uang ditujukan untuk kalangan ekonomi menengah ke atas dengan nilai minimal Rp. 1 juta. Wãqif dapat menentukan alokasi dana wakaf uang, misalnya untuk pendidikan atau kesehatan. Dengan dana itu, TWI melakukan investasi dengan menggandeng Batasa Capital. TWI bertindak sebagai nāẓir, sedangkan Batasa Capital bertindak sebagai manajer investasi dari Reksa Dana Dompet Dhu'afa' Batasa Syariah. ${ }^{2}$

TWI juga menerima wakaf saham seperti saham PT. Bank Muamalat Indonesia (BMI) Tbk. Deviden yang diperoleh dari saham itu digunakan untuk peningkatan kesejahteraan masyarakat. Deviden tidak boleh digunakan untuk investasi kembali. Apabila ingin melakukan investasi atas pembelian saham maka harus mencari wāqif baru. Untuk menghindari kesalahan dalam melakukan investasi, nāzir wakaf TWI menganalisa kelayakan investasi dan menganalisa pihak yang akan diajak untuk mengelola investasi.

Dalam melaksanakan kewajibannya selaku nāzir, TWI melakukan pengelolaan dan pengembangan atas harta benda wakaf yang dihimpunnya sesuai dengan tujuan, fungsi, dan peruntukannya dengan prinsip-prinsip syariah Islam. Pengelolaan aset di TWI dilakukan berdasarkan dua pendekatan, yaitu: (1) pendekatan produktif; dan (2) pendekatan non produktif.

Pendekatan produktif yaitu pengelolaan harta wakaf untuk hal-hal yang sifatnya produktif dan menghasilkan keuntungan. Keuntungan itu dimanfaatkan untuk kemaslahatan masyarakat banyak dengan tetap mempertahankan nilai pokok dari harta wakaf yang bersangkutan. Dari hasil investasi tersebut, keuntungannya dapat digunakan untuk program non produktif. Laporannya akan dapat dimonitor oleh para donatur melalui majalah TWI yang terbit secara berkala.

Penerimaan wakaf TWI mengalami pasang surut. Tahun 2001 tercatat penerimaan sebesar Rp. 50, 61 juta, kemudian tahun 2002 mengalami kenaik-

\footnotetext{
${ }^{1}$ Internet website, http://: www.tabungwakaf.com, diakses pada tanggal 20 Juli 2009.

${ }^{2}$ Disarikan dari Abdul Aziz Setiawan, "Tantangan Strategis Institusi Wakaf untuk Program Pengentasan Kemiskinan Masyarakat: Studi Kasus Tabung Wakaf Indonesia (TWI)," Jurnal Kordinat: Jurnal Komunikasi Antar Perguruan Tinggi Agama Islam Swasta, Vol. VIII No. 1, April 2007, h. 40-69.
} 
an mencapai Rp. 822, 45 juta, Tahun 2003 turun menjadi sebesar Rp. 624, 36 juta. Berikutnya Tahun 2004 dibukukan penerimaan sebesar Rp. 389,3 juta. Tahun 2005 penerimaan naik menjadi Rp. 518, 91 juta dan untuk tahun 2006 sampai dengan pertengahan Desember dibukukan penerimaan sebesar Rp. 2,289 miliar. $^{3}$

TWI bisa mengumpulkan uang rata-rata 2 miliar per tahun. Hingga akhir tahun 2008, dana yang telah dikumpulkan oleh TWI adalah sebesar Rp. 4.562.229.000,- (empat miliar lima ratus enam puluh dua juta dua ratus duapuluh sembilan ribu rupiah). Dana tersebut diperoleh dari masyarakat secara langsung kemudian diinvestasikan dan hasilnya disalurkan kepada objek yang memang sudah disiapkan oleh TWI. Namun TWI juga masih melayani wakaf langsung (bukan wakaf produktif) dalam bentuk uang. Misalnya, seseorang ingin membantu pengembangan rumah mualaf, maka dana yang disetor akan segera digunakan untuk peruntukan itu.

TWI memberikan sertifikat kepada wāqif yang telah berwakaf minimal 1 juta rupiah. Sertifikat Wakaf merupakan bukti bagi wāqif bahwa ia telah berwakaf. Dalam mengelola wakaf, TWI menggunakan pola pengelolaan asset management, yang memperlakukan wakaf sebagai aset yang menghasilkan surplus. Slogan TWI adalah angsa bertelur emas. Angsa tidak boleh mati, sehingga telor bisa dikonsumsi untuk kemaslahatan umat.

TWI menamakan wakaf uangnya dengan nama wakaf tunai. Istilah lain yang maknanya sesungguhnya sama namun juga dipergunakan oleh TWI adalah Wakaf Syukur Nikmat dan Wakaf Rindu Ilahi. Dana wakaf yang terkumpul itu kemudian diinvestasikan ke sektor riil. Hasil dari investasi itu disalurkan melalui program-program sosial, terpadu, dan produktif antara lain: Pertama. Program sosial. Program sosial yang dilakukan oleh TWI meliputi bantuan sarana dan prasarana institusi pelayanan umat. Program ini dapat dikatakan pengelolaan wakaf non-produktif. Non produktif berarti pengelolaan harta wakaf untuk hal-hal yang sifatnya tidak menghasilkan keuntungan. Manfaat yang ditimbulkan dari harta benda wakaf berupa nilai manfaat yang dapat dirasakan oleh masyarakat sebagai pemetik manfaat wakaf. Dalam konsep ini, TWI, mengalokasikan dana wakafnya untuk, misalnya, investasi pendirian sebuah rumah sakit cuma-cuma alias gratis. Ini ber-

${ }^{3}$ Ibid. 
arti tidak ada pemasukan sama sekali dan dengan demikian biaya operasional rumah sakit tersebut harus dicarikan dari sumber lainnya. Yang termasuk dalam program sosial ini diantaranya: (1) Rumah penyembuhan terpadu Parung, Rumah Sakit Khusus Dhuafa; (2) LKC (Layanan Kesehatan CumaCuma, layanan kesehatan gratis khusus dִ 'afä'. Layanan Kesehatan CumaCuma (LKC) untuk kesehatan kaum ḍ̣ 'afä' yang berbentuk rumah sakit mini dengan pelayanan 24 jam. LKC membuka UGD, rawat jalan, apotik, rawat inap, poli gigi, poli kandungan, dokter spesialis, konsultasi gizi, aksi luar gedung, bina ruhani pasien; (3) Wisma Muallaf, sebagai tempat pembinaan para muallaf yang teralienasi dari keluarga mereka. Para muallaf ini dapat mendalami akidah, syariah dan ibadah serta pembekalan kewirausahaan; (4) Rumah Baca Lingkar Pena, gedung berlantai tiga terletak di sektor 9 Bintaro. Rumah Baca merupakan wadah penggemblengan bagi anak dan remaja dalam mengoptimalkan kemampuan menulis, membaca puisi, dan berdongeng; (5) WakafCity (madinah wakaf). Walaupun ini baru rencana namun pantas diapresiasi. Wakaf City adalah kawasan terpadu yang memadukan fasilitas pelayanan sosial (social service) dan area bisnis (commercial area) dalam satu kawasan dengan nuansa islami. Saat ini baru berdiri social service yang telah berjalan berupa lembaga dan laboratorium pendidikan; (6) Lembaga Pendidikan Insani (LPI); (7) Institut Kemandirian (IK) Lembaga ini memberikan pelatihan singkat kewirausahaan bagi kaum ḍ u'afă' agar mampu menjadi wirausahawan. Diantara kegiatannya adalah pelatihan bengkel, percetakan, menjahit, perdagangan, dan tataboga; (8) SMART Ekselensia Indonesia, sekolah gratis unggulan untuk SMP-SMA. Sekolah ini adalah sekolah menengah yang dirancang secara khusus untuk menampung anak dari kaum ḍ ' 'afä' yang mempunyai potensi dengan sistem penyaringan yang sangat ketat dan dilakukan di seluruh provinsi. SMART Ekselensia adalah sekolah menengah 5 tahun setingkat SMP-SMA berasrama dan bebas biaya. Hingga sat ini sudah ada 4 angkatan dengan jumlah total 137 siswa laki-laki berprestasi dari 25 provinsi di seluruh Indonesia, dan telah melalui proses seleksi ketat meliputi seleksi administrasi, tes bidang studi, psikotes, home visit, dan tes kesehatan. Kurikulum SMART Ekselesia dimaksudkan agar siswa-siswi SMART dapat melanjutkan ke pendidikan tinggi, berakhlak islami, dan mampu mandiri. Alumni SMART diarahkan untuk bisa mendapatkan beasiswa di dalam dan luar negeri. Sistem penyaringan dilakukan di seluruh provinsi dengan seleksi ketat; (9) Beastudi Etos adalah program pembiayaan pendidikan, akomodasi dan pembinaan bagi mahasiswa-mahasiswa 
di 11 perguruan tinggi terkemuka di 9 provinsi di Indonesia, yaitu UI, IPB, ITB, Unpad, Undip, UGM, Unair, ITS, Unand, dan Unhas. Pelayanan yang diberikan adalah: pembiayaan: (a) uang masuk PT., SPP tahun pertama, uang saku 350-400 ribu rupiah/bulan selama 3 tahun. (b) Akomodasi: Asrama (c) Pembinaan: Self Development Training, kewirausahaan, praktek ibadah sehari-hari, Etos bertujuan untuk memutus rantai kemiskinan keluarga dan menumbuhkan jiwa kemandirian serta kepemimpinan bagi setiap Etoser (penerima beastudi Etos) dan (10) Makmal Pendidikan adalah program pengembangan guru dan sekolah-sekolah marjinal. Bentuk programnya berupa training pengembangan wawasan dan keterampilan guru serta pendampingan sekolah.

SMART Ekselensia, Beastudi Etos, dan Makmal Pendidikan merupakan tiga program unggulan yang langsung dikawal oleh jejaring Dompet Dhu'afa' (DD) yang bernama LPI (Lembaga Pengembangan Insani). Lembaga ini merupakan salah satu jejaring DD yang berkhidmat pada peningkatan kualitas manusia melalui pendidikan, khususnya kaum ḍu'afā', sebagai kelompok masyarakat yang terpinggirkan dalam peningkatan kualitas pendidikan Indonesia. LPI dompet Duafa berusaha menjadi suatu lembaga yang dapat memberikan alternatif solusi bagi rendahnya mutu pendidikan di Indonesia.

Kedua, Program Terpadu, Program terpadu merupakan program penyaluran wakaf untuk sarana dan prasarana institusi pelayanan umat dikombinasikan dengan program wakaf dalam bentuk sarana niaga: properti, perkebunan, perdagangan, pertanian dll, surplusnya dialirkan untuk kaum $\underline{d} u^{\prime} a f \bar{a}^{\prime} /$ untuk operasional institusi pelayanan umat dalam satu area program. Selain itu, masuk dalam penyaluran terpadu adalah pendirian rumah cahaya yang berupa sarana perpustakaan dan pelatihan penulisan bagi masyarakat umum yang dikombinasikan dengan aset properti yang akan disewakan dan surplusnya akan digunakan untuk mendukung program perpustakaan dan pelatihan penulisan. Termasuk dalam program terpadu juga adalah wakaf perkebunan cokelat dan kelapa. Saat ini TWI menjalankan program usaha perkebunan di kabupaten Banggai Sulawesi Tengah untuk perkebunan coklat dan kelapa. Hasil dari perkebunan cokelat dan kelapa ini digunakan untuk mendanai satu-satunya SMU yang ada di sana yaitu SMU Mansamat. ${ }^{4}$

\footnotetext{
${ }^{4}$ Ibid.
} 
Ketiga, profuktif. Produktif yang dimaksud di sini adalah dana yang telah dihimpun kemudian disalurkan pada usaha-usaha produktif, misalnya dalam bentuk sarana niaga: properti, perkebunan, perdagangan, pertanian, dll. Surplusnya dialirkan untuk kaum du'afä'. Yang masuk dalam kategori ini adalah sebagai berikut (1) Wakaf sarana niaga: Dengan wakaf tunai atau non tunai, TWI akan membangun atau mengadakan berbagai sarana niaga, seperti pertokoan, permesinan, kendaraan, dsb. Untuk disewakan kepada pihak ketiga. Hasil penyewaan sarana niaga ini akan dijariahkan untuk beragam kegiatan sosial sesuai dengan perminatan wāqif-nya; (2) Wakaf pertanian: TWI menjalankan program usaha pertanian bermitra, antara lain, dengan Lembaga Pertanian Sehat (LPS), jejaring Dompet Dhu'afa' lain yang bergiat dalam pertanian sehat. LPS juga menyiapkan sarana produksi pertanian dari bahan organik; (3) Wakaf peternakan: TWI menginvestasikan dana wakaf untuk peternakan bekerjasama dengan jejaring Dompet Dhu'afa' lain, yakni Kampoeng Ternak. Lembaga ini telah sukses memberdayakan peternakan dan memiliki mitra di berbagai kota di Indonesia di samping aktif dalam pendistribusian hewan kurban, melakukan serangkaian riset, pendidikan dan pelatihan serta pendampingan sektor peternakan dan (4) Wakaf perkebunan Karet: TWI menjalankan program wakaf pohon karet di Lahat, Sumatera Selatan. Wakaf ini disamping untuk mensejahterakan kaum papa, juga untuk menjaga bumi agar tetap lestari.

Adapun program produktif TWI dalam pengelolaan wakaf yang berfungsi sebagai investasi sekaligus untuk mendukung program pengentasan kemiskinan antara lain:5 (1) Penyertaan Modal di Baitul Maal wat Tamwil (BMT) Bina Dhuafa Beringharjo Yogyakarta. Tahun 2006, TWI menanam investasi senilai Rp. 175 juta; (2) Pemberian Modal Pembuatan tahu di Kampung Tahu, Kampung Iwul Desa Bojong Sempu Parung, Bogor; (3) Investasi di Usaha Mikro Bakmi Tebet (Langgara). Ditargetkan TWI akan memiliki produk yang dikelola sendiri dan dapat dijual dengan sistem waralaba; (4) Pengelolaan wakaf saham. Wakaf saham pertama di TWI adalah dari wāqif Ibu Mus Kusmanti, yang mewakafkan sejumlah saham dari 39 perusahaan untuk diambil devidennya

\footnotetext{
${ }^{5}$ Abdul Aziz Setiawan, "Tantangan Strategis Institusi Wakaf untuk Program Pengentasan Kemiskinan Masyarakat: Studi Kasus Tabung Wakaf Indonesia (TWI)".
} 
untuk kemaslahatan yang membutuhkan. Saham, sebagai salah satu bentuk surat berharga, saat diwakafkan, sebagaimana harta bergerak lainnya (emas, uang tunai), menjadi objek yang hanya dipetik manfaatnya (deviden tahunan) tanpa menghilangkan pokoknya (saham itu sendiri). TWI menyalurkan dividen tersebut ke sejumlah program, diantaranya untuk sekolah bagi keluarga miskin dan (5) Peternakan kambing dengan sistem paroan. Program ini dinamakan investasi Kampung Ternak. TWI mendanai tujuh pendamping peternak dan 29 mitra di daerah. Pendamping dan mitra membina 1300 peternak di 16 provinsi.

\section{Pos Keadilan Peduli Umat (PKPU)}

Krisis yang terjadi pada 1997 memengaruhi kondisi perekonomian bangsa dan rakyat Indonesia. Menyikapi krisis yang berkembang, 17 September 1998, sejumlah anak-anak muda yang enerjik melakukan aksi sosial di sebagian besar wilayah Indonesia. Menindaklanjuti aksinya, mereka kemudian menggagas entitas kepedulian publik yang bisa bergerak secara sistematis. Maka pada 10 Desember 1999 lahirlah lembaga sosial yang bernama Pos Keadilan Peduli Umat yang disingkat PKPU. Pada tanggal 12 September 2000, PKPU disetujui sebagai lembaga sosial dengan Surat Keputusan Menteri Sosial Indonesia dengan nomor 2000.40405.916.

Setelah mendapatkan ijin berdiri, PKPU semakin banyak dipercaya masyarakat. Dalam kurun waktu dua tahun, PKPU ditetapkan sebagai salah satu Lembaga Amil Zakat Nasional oleh kementerian agama Indonesia melalui Surat Keputusan Menteri Agama No. 441 pada 8 Oktober 2001. Visi yang dikembangkan PKPU adalah menjadi lembaga terpercaya dalam membangun kemandirian. Sementara misinya adalah misi kemanusiaan yang meliputi: 6 (1) Mendayagunakan program rescue (emergency), rehabilitasi dan pemberdayaan untuk mengembangkan kemandirian. PKPU melakukan tindakan penyelamatan pada keadaan darurat di daerah bencana alam atau yang disebabkan oleh manusia, seperti kebakaran banjir, gempa bumi, tsunami, tanah longsor, pengungsi atau daerah konflik. PKPU telah menangani bencana alam baik dalam negeri maupun luar negeri (Afganistan, Pakistan Libanon), dengan menjangkau 21 provinsi di Indonesia, 44 kota dengan melibatkan 2.321 relawan, dan membantu 1.880 .400

\footnotetext{
${ }^{6}$ Wawancara dengan Suharsono (Manajer wakaf dan Dakwah PKPU), Jum'at, 24 Juli 2009, 14.15.00 di kantor PKPU, Jl. Condet Raya Jakarta.
} 
pengungsi; (2) Mendayagunakan program rehabilitation. Program ini dijalankan pasca bencana di daerah minus dengan melakukan perbaikan baik secara fisik maupun non fisik; (3) Mendayagunakan program re-development (community based development). Program ini merupakan proses integral untuk membangun komunitas, dengan melakukan pengamatan kehidupan sosial, ruhani, lingkungan, pendidikan, kesehatan, ekonomi, budaya dan aspek politik; (4) Mengembangkan kemitraan dengan masyarakat, perusahaan, pemerintah, dan lembaga swadaya masyarakat dalam dan luar negeri; dan (5) Memberikan pelayanan informasi, edukasi dan advokasi kepada masyarakat penerima manfaat (beneficiaries).

Dalam mengaktualisasikan fungsinya, PKPU telah mempersiapkan berbagai variasi program, yang dijalankan pada 15 cabang di seluruh Indonesia. PKPU memusatkan aktiviitasnya pada pelayanan masyarakat agar mampu mandiri, pulih dari keterpurukan serta mampu bertahan dalam kondisi yang sulit. Program dijalankan dengan menggalang kerjasama dalam maupun luar negeri atas dasar ketulusan dan kejujuran.

Dalam perkembangannya, PKPU menyadari bahwa potensi dana umat yang berasal dari Zakat, Infaq dan Shadaqah sangat besar. Sebagai negara berpenduduk Muslim terbesar di dunia, Indonesia bisa mengoptimalkan dana ZIS-nya untuk memberdayakan masyarakat miskin. Maka pada 8 Oktober 2001, PKPU mendapat pengukuhan sebagai Lembaga Amil Zakat Nasional sesuai dengan SK. Menteri Agama RI No 441. Hal itu membuktikan bahwa kepercayaan masyarakat kepada PKPU semakin besar.

Dalam rangka memfasilitasi antara dermawan (aghniyā) di satu pihak dengan fakir miskin ( $\left(u^{\prime}{ }^{\prime} a f a ̄\right)$ di lain pihak, kerja yang amanah dan profesional merupakan keharusan bahkan tuntutan yang diwujudkan dalam kultur dan etos kerja PKPU. PKPU menunaikan dan menyampaikan kewajiban serta hak sesuai dengan amanah secara profesional, adil dan transparan hingga kepercayaan donatur dan bantuan yang diberikan pada du $u^{\prime} a f \tilde{a}^{\prime}$ meningkat setiap waktu.

\section{Baitul Mal Muamalat (BMM)}

BMM kepanjangan dari Baitul Mal Muamalat. BMM adalah sebuah lembaga di bawah Bank Muamalat Indonesia (BMI) yang mengelola perbankan sektor volunter. Dalam kaitan wakaf uang, BMM bukanlah bank. Ia adalah nāzir wakaf. Sementara BMI adalah salah satu LKS-PWU di Indonesia. BMI berdiri berkat upaya MUI dan ICMI pada tahun 1992. BMI menjadi pelopor 
LKS di Indonesia yang kemudian disusul oleh bank syariah lainnya. Sekarang hampir semua bank konvensional memiliki bank syariah.7 BMI merupakan lembaga keuangan syariah pertama di Indonesia. ${ }^{8}$

BMM memiliki beberapa program yang terkait dengan sektor volunter. ${ }^{9}$ Program wakaf uang diwadahi dalam program yang diberi nama Waqtumu (Wakaf Tunai Muamalat) dan Syar'i Peduli.

"Waqtumu" merupakan program penggalangan dana masyarakat melalui wakaf uang yang bisa dibayarkan di seluruh kantor dan perwakilan BMI. "Waqtumu" memiliki dua manfaat: (a) Hasil pengelolaannya dapat terdistribusi dengan tepat kepada yang berhak; (b) Memberikan kenyamanan dan ketenangan kepada peserta sebagai amaliah yang terus mengalir dunia dan akhirat.

Sementara "Syar'i Peduli" merupakan produk syar'i yang dikemas untuk model wakaf waktu terbatas. Misalnya ada seorang nasabah yang mempunyai tabungan syar'i, lalu ia blokir dananya dan keuntungannya ia gunakan untuk aktivitas sosial. Dana "Syar'i Peduli" terkumpul jauh lebih besar hingga 2 miliar (per Mei 2009). Jadi, Syar'i peduli merupakan tabungan Syar'i Bank Muamalat yang nominalnya ditahan (di-hold) oleh bank untuk jangka waktu tertentu. Tabungan Syar'i peduli dapat dikatakan sebagai wakaf berjangka yang bagi hasilnya masuk ke rekening infaq BMM. ${ }^{10}$ Karena wakaf berjangka, maka dananya bergerak keluar dan masuk sesuai keinginan wäqif.

"Waqtumu" diluncurkan pada tahun 2002. Pada tahun pertama, "Waqtumu" mencatat telah memiliki: ${ }^{11}$ (1) Peserta: 34 Wãqif; (2) Total Dana: 200 juta; (3) Investasi: Deposito BPRS; (4) Hasil Investasi: 6 juta; (5) Penyaluran dalam bidang pemberdayaan Pendidikan, Kesehatan dan Ekonomi; (6) Program Selling Tradisional. "Waqtumu" memiliki tujuan sebagai berikut: ${ }^{12}$ (1) Meningkatkan penghimpunan dana sosial masyarakat; (2) Menjamin ketersediaan dana yang besar untuk kepentingan sustainability program pemberdayaan dan (3) Mendidik masyarakat agar mau menggunakan produk bank syariah.

\footnotetext{
${ }^{7}$ Tim Depag, Perkembangan Pengelolaan Wakafdi Indonesia, (Jakarta: DepagRI, 2003), h. 69.

${ }^{8}$ Wawancara dengan Iwan Agustiawan Fuad, Kamis 23 Juli 2009, jam 15.00-15.30.

${ }_{9}$ Wawancara dengan Yayan Daryunanti (Manajer Administrasi dan Keuangan baitul Mal Muamalat, BMM Jakarta) Kamis, 23 Juli 2009, 14.00-15.00 di Kantor BMM, Gd. Dapentel Lt. 2 Jl. Letjend S. Parman Kav. 56 Slipi Jakarta 11410.

${ }^{10} \mathrm{Ibid}$.

${ }^{11}$ bid.

${ }^{12}$ Ibid.
} 
Adapun ketentuan terkait dengan "Waqtumu" adalah sebagai berikut:13 (1) Wāqif menentukan jangka waktu terbatas atau jangka waktu tidak terbatas dan penerima manfaat dana wakaf (beneficiary) untuk pembinaan ekonomi, pendidikan, atau kesehatan; (2) Wāqif yang mewakafkan dana sebesar Rp. 1 M dapat menentukan penerima manfaat invesatasi dana wakaf; (3) Wāqif yang mewakafkan dana Rp. 100 juta dapat menunjuk keluarganya sebagai penerima manfaat investasi wakaf; (4) Wãqif adalah perorangan atau institusi; (5) Pelaksana administrasi Dana Wakaf adalah PT. Bank Muamalat Indonesia, Tbk; (6) Manager Pendayagunaan Dana Wakaf (nāzir) adalah Baitul Mal Muamalat (BMM); (7) Waktu pengelolaan wakaf tunai terbatas minimal 3 tahun; (8) Jenis Investasi Dana Wakaf ditentukan oleh nāzir (pengelola dana wakaf) dengan pertimbangan keamanan dan keuntungan serta kemanfaatan bagi kemaslahatan umat; (9) Dana "Waqtumu" dikembangkan melalui lembaga-lembaga keuangan syariah sehingga mendapatkan bagi hasil dan (10) Wãqif mendapat sertifikat wakaf tunai dan pelaporan pendayagunaan.

Karena tuntutan masyarakat, maka sertifikat "Waqtumu" memiliki nilai yang bertingkat. Terdapat 4 nilai sertifikat, yakni: Rp. 100.000,-, Rp. 250.000, Rp. 500.000,- dan Rp. 1.000.000,-. Hingga 30 Juni 2007, nilai sertifikat di atas 1 juta rupiah hingga 10 juta paling banyak diminati masyarakat. Ini dapat disimpulkan bahwa sesungguhnya wakaf uang lebih banyak diminati oleh mereka yang memiliki pendapatan besar dan belum diminati oleh mereka yang memiliki pendapatan kecil. Hingga 30 Juni 2007, perbandingan jumlah wāqif dari masing-masing sertifikat dapat dijelaslan pada tabel $1 .{ }^{14}$

Tabel 1.

Jumlah Wāqif dan Sertifikat Waqtumu

\begin{tabular}{cllrrr}
\hline No. & \multicolumn{3}{c}{ Sertifikat Waqtumu } & Jumlah Wōqif & \multicolumn{1}{c}{ Jumlah } \\
\hline 1 & Rp. $100.000,-$ & s.d. & Rp. $500.000,-$ & 75 & $22.568 .698,53$ \\
2 & Rp. $501.000,-$ & s.d. & Rp. 1.000.000,- & 105 & $73.423 .322,00$ \\
3 & Rp. 1.001.000,- & s.d. & Rp. 10.000.000,- & 251 & $809.095 .077,07$ \\
4 & Rp. 10.001.000,- s.d. & Rp. 50.000.000,- & 5 & $145.000 .000,00$ \\
\hline
\end{tabular}

Sumber: Baitul Mal Muamalat (BMM)

${ }^{13}$ Ibid.

${ }^{14}$ Ibid.

Walisongo, Volume 19, Nomor 1, Mei 2011 
Sejak berdirinya hingga tanggal 30 Juni 2007, penghimpunan dana "Waqtumu" dapat dilihat dalam tabel 2 berikut: 15

Tabel 2.

Penghimpunan Dana "Waqtumu” Per 30 Juni 2007

\begin{tabular}{ccr}
\hline Tahun & Jumlah Wāqif & \multicolumn{1}{c}{ Nominal Wakaf } \\
\hline 2002 & 8 & $16.688 .917,17$ \\
2003 & 18 & $18.723 .008,81$ \\
2004 & 19 & $19.931 .612,62$ \\
2005 & 42 & $101.350 .352,67$ \\
2006 & 55 & $60.334 .966,63$ \\
2007 & 99 & $84.157 .614,00$ \\
\hline Total & $\mathbf{2 4 1}$ & $\mathbf{3 0 1 . 1 8 6 . 4 7 1 , 6 0}$ \\
\hline
\end{tabular}

Sumber: Baitul Mal Muamalat (BMM)

Perkembangan Dana "Waqtumu” Per-Juni 2007 dapat dijelaskan pada tabel 3 sebagai berikut:

Tabel 3.

Perkembangan Dana “Waqtumu” Per-Juni 2007

\begin{tabular}{clr}
\hline No. & \multicolumn{1}{c}{ Keterangan } & \multicolumn{1}{c}{ Jumlah } \\
\hline 1 & Penghimpunan & Rp. 1.051.787.097,60 \\
2 & Jumlah Wāqif & 437 orang \\
3 & Rata-rata Wakaf & Rp. 2.406.835,-/orang \\
4 & Penempatan LKMS & Rp. 272.278.890 \\
5 & Penempatan BMI & Rp. 779.508.207 \\
6 & Bagi Hasil/tahun & Rp. 193.493.370 \\
7 & Fee Marketing & Rp. 2.000.000 \\
8 & Pendayagunaan & Rp. 170.000 .000 \\
9 & Sisa Dana & Rp. 21.493.370 \\
\hline
\end{tabular}

Sumber: Baitul Mal Muamalat (BMM)

Pertanggungjawaban keuangan BMM dilakukan melalui mekanisme sebagai berikut: (1) Laporan perkembangan dan penyaluran dana wakaf di-

\footnotetext{
${ }^{15}$ Ibid.
} 
kirim atau diumumkan melalui media masa setiap awal tahun ${ }^{16}$; (2) Sebagai bukti kepesertaan adalah dikeluarkannya sertifikat wakaf tunai muamalat; (3) Layanan informasi posisi dana peserta dan lainnya dapat dilakukan via telepon; (4) Biaya operasional 12,5\%; (5) Fee marketing 4\%; (6) Dana cadangan untuk jaminan investasi 7,5\%; (7) Pendayagunaan untuk beberapa bidang 80\%; (8) Dana wakaf dikelola oleh para profesional; (9) Manfaat wakaf dinikmati oleh yang berhak menerimanya dan (10) Pokok dana wakaf dapat meningkat.

Dana "Waqtumu" BMM diinvestasikan dalam 3 bentuk: (1) Deposito bagi hasil (bank syariah); (2) Pasar modal syariah (reksadana syariah, obligasi, dan saham syariah) dan (3) Sektor riil dengan executing system. Adapun hasil investasinya disalurkan dalam bidang-bidang: (1) Ekonomi (KUM3, BMT 261); (2) Pendidikan (Kafalla Program); (3) Sosial (Infaq Masjid Indonesia); (4) Kesehatan (Klinik Sehat) dan (5) Kemanusiaan (Aksi Tanggap Muamalat)

Selain "Waqtumu" dan "Syar'i Peduli", BMM juga memiliki program KUM3. KUM3 adalah program pemberdayaan usaha mikro berbasis masjid yang bertujuan untuk membangun keimanan dan ketakwaan. Program ini dirancang agar para pelaku usaha mikro memiliki mentalitas serta paradigma keislaman yang integral. Pada saat yang bersamaan, KUM3 mendorong peningkatan omset usaha melalui pemberian modal bergulir. Pemusatan aktivitasnya di masjid guna mencegah mentalitas negatif. Selain pengguliran modal, program ini juga melakukan pendampingan usaha bagi usaha mikro untuk melahirkan Komunitas Usaha Mikro yang sehat.

\section{Kesimpulan}

Dari beberapa uraian mengenai manajemen wakaf tunai seperti telah dijelaskan tersebut di atas, maka dapat ditarik kesimpulan sebagai berikut: Pertama, dalam rangka menggalang dana wakaf uang, TWI sebagai nāẓir wakaf uang, menempuh cara sosialisasi dengan pendekatan kultural seperti pengajian disamping juga melalui brosur dan leaflet, sementara PKPU belum melakukan penggalangan dan baru menyiapkan sistem pengelolaannya. Bila dibandingkan dengan TWI dan PKPU, penggalangan yang dilakukan BMM

\footnotetext{
${ }^{16}$ Ibid.
} 
relatif lebih progresif, karena berbasis pada perbankan dan telah memiliki nasabah. BMM melakukan sosialisasi pada nasabah Bank Muamalat melalui brosur, kerjasama dengan pihak lain, peluncuran program khusus, dan SMS broad cast. BMM juga sudah melakukan berbagai program yang cukup kreatif guna meningkatkan jumlah wāqif uang yang berwakaf ke BMM.

Kedua, dalam hal mekanisme pertanggungjawaban kepada masyarakat, ketiga lembaga itu menempuh cara yang berbeda. TWI melaporkan secara berkala pada wāqif (4 bulanan dan tahunan), PKPU meminta jasa akuntan publik independen, sementara BMM mengandalkan akuntabilitas sistem perbankan.

Ketiga, dalam menjalankan kewajiban menjaga pokok harta, ketiganya memiliki kesamaan, yakni belum melibatkan lembaga penjamin (asuransi) Syariah dengan alasan yang beragam. TWI beralasan karena kewajiban nāzir hanya menjalankan usaha terbaik, PKPU beralasan masih mempercayai deposito, sementara BMM menganggap dananya masih terlalu kecil untuk dijaminkan.

Keempat, dalam hal sasaran penyaluran, TWI mengarahkan pada aktivitas pemberdayaan pendidikan, kesehatan, dan ekonomi, sementara PKPU mengarahkannya untuk modal kerja, dan BMM menyalurkan sesuai keinginan wāqif dan bila wāqif tidak memiliki syarat maka BMM menentukan secara sepihak dengan mengutamakan pemberdayaan pendidikan, kesehatan, dan ekonomi. Dalam hal metode penyalurannya, TWI menempuh cara tak langsung, yakni bekerjasama dengan Dompet Dhu'afa' Republika, sementara PKPU dan BMM menempuh cara langsung.

Kelima, dalam hal problem manajerial, TWI dan BMM merasa tidak memilikinya dengan alasan yang berbeda. TWI merasa telah cukup berpengalaman dalam urusan manajerial sementara BMM merasa percaya dengan sistem perbankan. Sementara PKPU mengalami kendala manajerial karena merasa sistem yang ada belum sia.

Keenam, walaupun tidak semua memiliki kendala manajemen, namun solusi manajemen selalu mereka tempuh. TWI melakukan dua macam, yakni konsultasi dengan atasan dan diskusi internal tim. Sementara PKPU melakukan diskusi internal, dan BMM melakukan maksimalisasi sistem perbankan. 
Ketujuh, ketiga lembaga itu (TWI, BMM dan PKPU) memiliki optimisme yang besar akan masa depan wakaf uang di Indonesia. Mereka yakin, dalam dua puluh lima tahun ke depan, wakaf uang di Indonesia akan cemerlang dan berpotensi membantu negara dalam melepaskan diri dari jebakan hutang dan membantu penanggulangan kemiskinan. Namun optimisme itu harus ditindaklanjuti dengan aksi nyata dalam menjawab 7 kelemahan mendasar praktek wakaf uang di Indonesia, yakni: rendahnya sosialisasi kepada masyarakat tentang wakaf uang, ${ }^{17}$ minimnya nāzir yang profesional, belum adanya sistem mobilisasi dana yang efektif, lemahnya sistem manajerial, rendahnya komitmen pada manajemen risiko, belum terlindunginya purchasing power of money, dan masih adanya keragaman prioritas sasaran penyaluran.

Dari kesimpulan tersebut di atas, maka kajian ini menghasilkan tujuh butir saran kepada BWI, pemerintah, seluruh pemerhati wakaf uang, dan para praktisi wakaf uang di Indonesia. Ketujuh butir itu adalah: (1) Semua pihak perlu merumuskan rencana aksi yang konkret dalam upaya peningkatan sosialisasi wakaf uang kepada masyarakat terutama menyangkut manfaat, peluang, proses, dan prosedur wakaf uang; (2) Sebagai lembaga yang diberi tugas oleh UU untuk meningkatkan kualitas kinerja nāẓir, BWI perlu mengambil prakarsa dalam meningkatkan intensitas dan efektivitas training nāzir secara berkesinambungan; (3) Sebagai lembaga yang diberi tugas oleh UU untuk memajukan wakaf di Indonesia, BWI perlu mengambil prakarsa dalam menciptakan sistem mobilisasi dana yang efektif, misalnya dengan menggunakan sistem reward (hadiah) melalui undian bagi para wāqif yang telah mencapai nominal tertentu atau bekerjasama dengan Dirjen Pajak agar wakaf bisa dihargai sebagai pengurangan pajak; (4) Sebagai lembaga yang diberi tugas oleh UU untuk memajukan wakaf di Indonesia, BWI perlu memprakarsai terciptanya sistem training nāzir yang standar, berkala, dan berkelanjutan secara terus-menerus khususnya terkait dengan upaya peningkatan kualitas manajerial; (5) BWI perlu menekankan kepada semua nāzir wakaf uang di Indonesia agar sistem penjaminan risiko benar-benar dijalankan; (6) BWI perlu membuat terobosan terkait dengan konversi nilai uang dengan emas atau

17 Wawancara dengan Kholilun Nafis (Wakil Sekretaris BWI), Rabu, 22 Juli 2009, jam 8.0008.30 di Kantor BWI Pinang Ranti Jakarta. 
Dinar guna melindungi purchasing power of money dana wakaf uang. Walaupun UU tidak mengaturnya, namun demi kemaslahatan yang lebih panjang, langkah ini perlu ditempuh dan (7) Guna mempercepat penyelesaian masalah bangsa, BWI perlu melakukan pemantauan agar seluruh nāzir wakaf uang di Indonesia mengimplementasikan prioritas sasaran penyaluran seperti yang telah ditetapkan oleh BWI.[w] 


\section{BIBLIOGRAFI}

Internet website: www.tabungwakaf.com, diakses tanggal 20 Juli 2009.

Internet website: http://www.pkpu.or.id/profilx.php, diakses tanggal 20 Juli 2009.

Setiawan, Abdul Aziz, "Tantangan Strategis Institusi Wakaf untuk Program Pengentasan Kemiskinan Masyarakat: Studi Kasus Tabung Wakaf Indonesia (TWI)," dalam Jurnal Kordinat, Jurnal Komunikasi Antar Perguruan Tinggi Agama Islam Swasta Vol. VIII No. 1, April 2007 h. 40-69.

Tim Depag, Perkembangan Pengelolaan Wakaf di Indonesia. Jakarta: Depag RI, 2003.

Wawancara dengan Iwan Agustiawan Fuad (General Manajer BMM), Kamis 23 Juli 2009, jam 15.00-15.30 di Kantor BMM, Gd. Dapentel Lt. 2 Jl. Letjend S. Parman Kav. 56 Slipi Jakarta 11410.

Wawancara dengan Suharsono (Manajer wakaf dan Dakwah PKPU), Jum'at, 24 Juli 2009, 14.15.00 di Kantor PKPU, Jl. Condet Raya Jakarta.

Wawancara dengan Yayan Daryunanti (Manajer Administrasi dan Keuangan Baitul Mal Muamalat, BMM Jakarta) Kamis, 23 Juli 2009, 14.00-15.00 di Kantor BMM, Gd. Dapentel Lt. 2 Jl. Letjend S. Parman Kav. 56 Slipi Jakarta 11410.

Wawancara dengan Kholilun Nafis (Wakil Sekretaris BWI), Rabu, 22 Juli 2009, jam 8.00-08.30 di Kantor BWI Pinang Ranti Jakarta.

Wawancara dengan Uswatun Hasanah (Divisi Litbang BWI Periode 2007-2010), Rabu, 22 Juli 2009 jam 12.00-13.00 di LKIHI-FHUI Kampus UI Depok.

Wawancara dengan Hendra, Jumat, 24 Juli 2009 jam 9.00-10.00 di kantor TWI Jl. Radio Dalam Jakarta. 
